\title{
Quantitative Analysis of the Learning Curve Obtained for Foreign Language Studies
}

\author{
Zh.A. Mukanova, a), D.B. Berg ${ }^{1, \text { b) }}$, M. Kit', c), E.B. Berg's, d), M.A. Medvedeva ${ }^{1, \text { e) }}$ \\ ${ }^{1}$ Ural Federal University, Mira 19, Ekaterinburg, Russia, 620002 \\ ${ }^{2}$ Language Interface Inc., 1st Ave. 1221, Seattle, USA, 98101 \\ ${ }^{3}$ Ural State Law University, Komsomolskaya Street 21, Ekaterinburg, Russia, 620137 \\ a)zhanna.mukanova.83@mail.ru \\ b)bergd@mail.ru \\ c)clodpool@gmail.com \\ d)elenabkct@gmail.com \\ e)Corresponding author: marmed55@yandex.ru
}

\begin{abstract}
The article presents the results of an experimental construction and quantitative analysis of the learning curve (LC) obtained from individuals learning a foreign language. The experiment was conducted at the Ural Federal University named after the first President of Russia B.N. Yeltsin. Three types of LC were constructed for different level of English skills of the subjects: Pre-Intermediate, Intermediate and Upper-Intermediate. Comparison of these curves demonstrates that the subject's knowledge acquisition keeps running for 14 hours after the flash memory session. The paper presents two dependencies for constructing an approximation of the learning curve: logarithmic and polynomial. Based on a comparison of the approximation of the experimental LCs with functions of various types, we suggest that they all provide satisfactory results. Based on the results plans for further study of the problem were proposed.
\end{abstract}

Keywords: learning curve, LexSite dictionary, learning foreign languages, vocabulary, learning efficiency.

\section{INTRODUCTION}

The development of the market economy in Russia poses new requirements to the education system. Presently the demand for high quality education is growing as most employers associate the level of development of their organization with the skills of their staff. The learning curve analysis helps establish the relationship between the performance of the personnel and the time invested in its training. Learning curve (LC) is a graphical representation of the effectiveness of a person, group of people or organization in carrying out a new activity as they learn.

LC methods have been successfully applied in many fields. For example, Itzhak Venezia in [1] provides a statistical justification for the existence of the LC phenomenon. Sem F. Hardon, Tim Horeman, H. Jaap Bonjer and W.J.H. Jeroen Meijerink in [2] used LC to determine the scope of training needed to achieve certain levels of competence in laparoscopic tissue manipulation and the operation of the instrument. In the works of Linda Argote and Dennis Epple [3], Paul Simon Adler and Kim Clark [4], the authors viewed LCs as part of production operations. The analysis presented in the aforementioned works was based on experimental data and used various mathematical models.

This research is aimed at a quantitative analysis of the learning curve obtained in the course of foreign language studies. 


\section{METHODS}

In this research an experiment was conducted the English language studies. The subjects of the experiment were students of the Ural Federal University named after the first President of Russia B.N. Yeltsin [5] aged 18-19 years. All participants were divided into three groups by their level of English proficiency (table 1).

TABLE 1. Number of participants by the level of English skills.

\begin{tabular}{rlc}
\hline \multicolumn{1}{c}{ № } & English level & Number of participants \\
\hline 1 & Pre-Intermediate & 4 \\
2 & Intermediate & 3 \\
3 & Upper-Intermediate & 2 \\
Total & & 9 \\
\hline
\end{tabular}

The subjects were tasked to learn the content of a English-Russian dictionary covering the "City" topic. The dictionary contained 52 headwords. The learning was carried out using flash cards on a daily basis ( 1 session a day) for 20 minutes in the English-Russian direction with simultaneous playing of the pronunciation of the words studied. In every session each flash card was shown 2 to 3 times. Verification of the acquired knowledge was carried out using the embedded testing tool, which also consisted of flash cards. Each flash card shows a headword in English and proposed translations. The subjects had to select one correct translation within 10 seconds. The entire test session takes about 9 minutes. Taking the test daily resulted in obtaining a comprehensive assessment of the acquisition of the lexis contained in the dictionary. In total, each participant conducted 5 learning sessions. This method enabled us to build a learning curve for foreign language learners.

This study of the learning curve used the LexSite reference and training system [6]. This system was developed to help translators, engineers, teachers, researchers and students learn foreign lexis in the English-Russian language pair [7]. To track the effectiveness of the word learning process, the LexSite system provides analitical tools that include a learning curve generator.

\section{RESULTS}

Table 2 shows the average results of the tests performed during the experiment.

TABLE 2. Test results.

\begin{tabular}{cccc}
\hline Period of study & $\begin{array}{c}\text { LC (Pre-Intermediate), } \\
\mathbf{\%}\end{array}$ & $\begin{array}{c}\text { LC (Intermediate), } \\
\mathbf{\%}\end{array}$ & $\begin{array}{c}\text { LC (Upper-Intermediate), } \\
\mathbf{\%}\end{array}$ \\
\hline 1 & 69 & 79 & 89 \\
2 & 90 & 97 & 95 \\
3 & 94 & 93 & 98 \\
4 & 91 & 99 & 99 \\
5 & 98 & 99 & 100 \\
\hline
\end{tabular}

The obtained experimental data were approximated with two functions: logarithmic and polynomial (table 3). To assess the quality of the approximation, the coefficient of determination R2 and the standard deviation (SD) were calculated.

TABLE 3. Approximation of the experimental data.

\begin{tabular}{cclccccc}
\hline Function & Formula & \multicolumn{1}{c}{ LC } & A & B & C & SD & R2 \\
\hline logarithmic & $y=A+B \ln x$ & Pre-Intermediate & 72,6 & 16,5 & & 10,5 & 0,848 \\
& & Intermediate & 81,9 & 11,9 & & 7,6 & 0,7983 \\
& & Upper-Intermediate & 89,5 & 6,9 & & 4,4 & 0,9831 \\
\hline polynomial & $y=A x^{2}+B x+C$ & Pre-Intermediate & $-2,5$ & 21,1 & 52,8 & 10,7 & 0,8612 \\
& & Intermediate & $-1,9$ & 15,5 & 67,3 & 7,4 & 0,8121 \\
& & Upper-Intermediate & $-0,8$ & 7,3 & 82,8 & 4,2 & 0,9876 \\
\hline
\end{tabular}

Figures 1 and 2 show the learning curves obtained as a result of the experiment. 


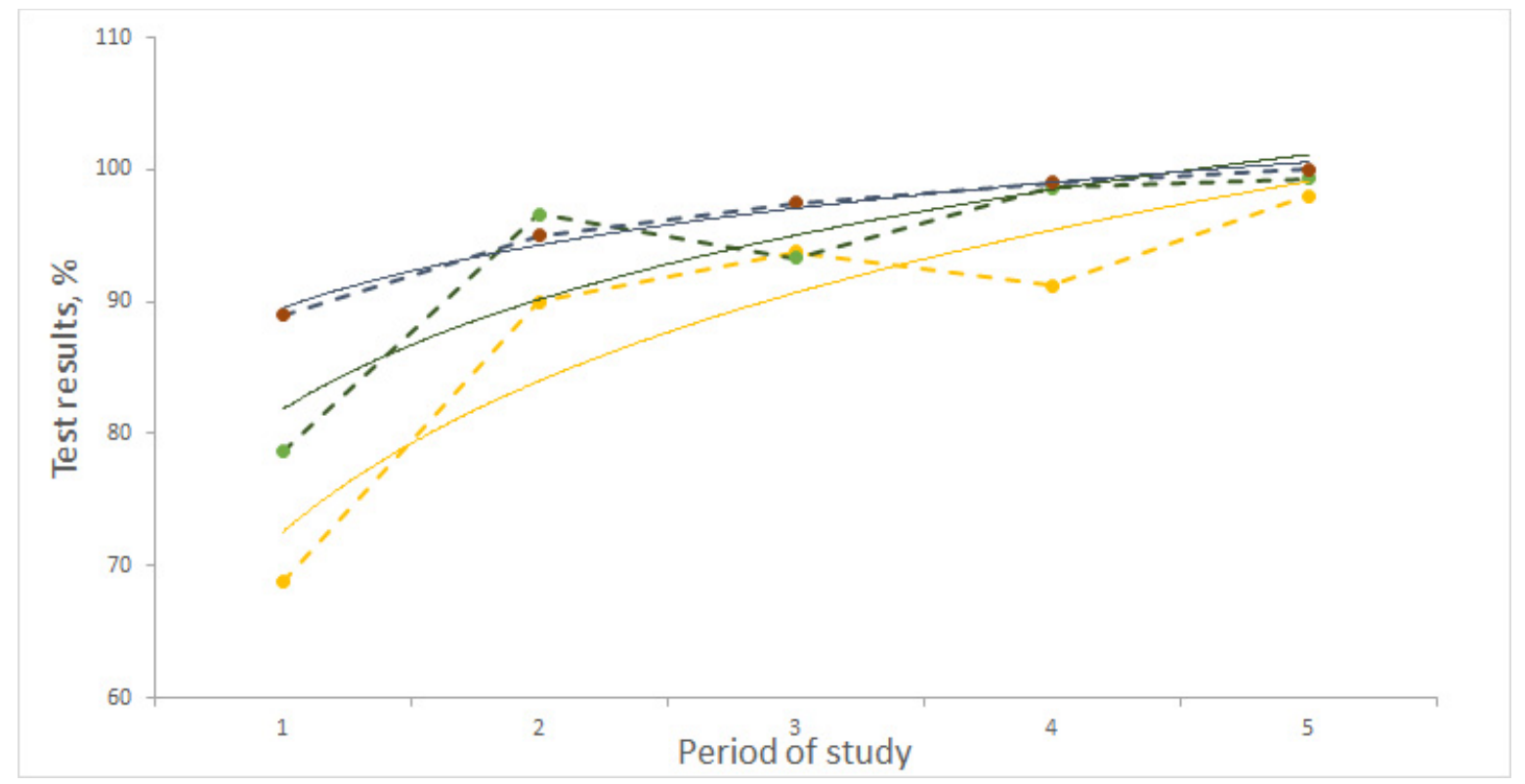

FIGURE 1. Learning curves obtained in the experiment (logarithmic approximation)

( $\_-\ldots$ - raw data (LC Pre-Intermediate); __ - approximated data (LC Pre-Intermediate),

_ - . - raw data (LC Intermediate); __ - approximated data (LC Intermediate,

_- .. - raw data (LC Upper-Intermediate); ___ - approximated data (LC Upper-Intermediate)).

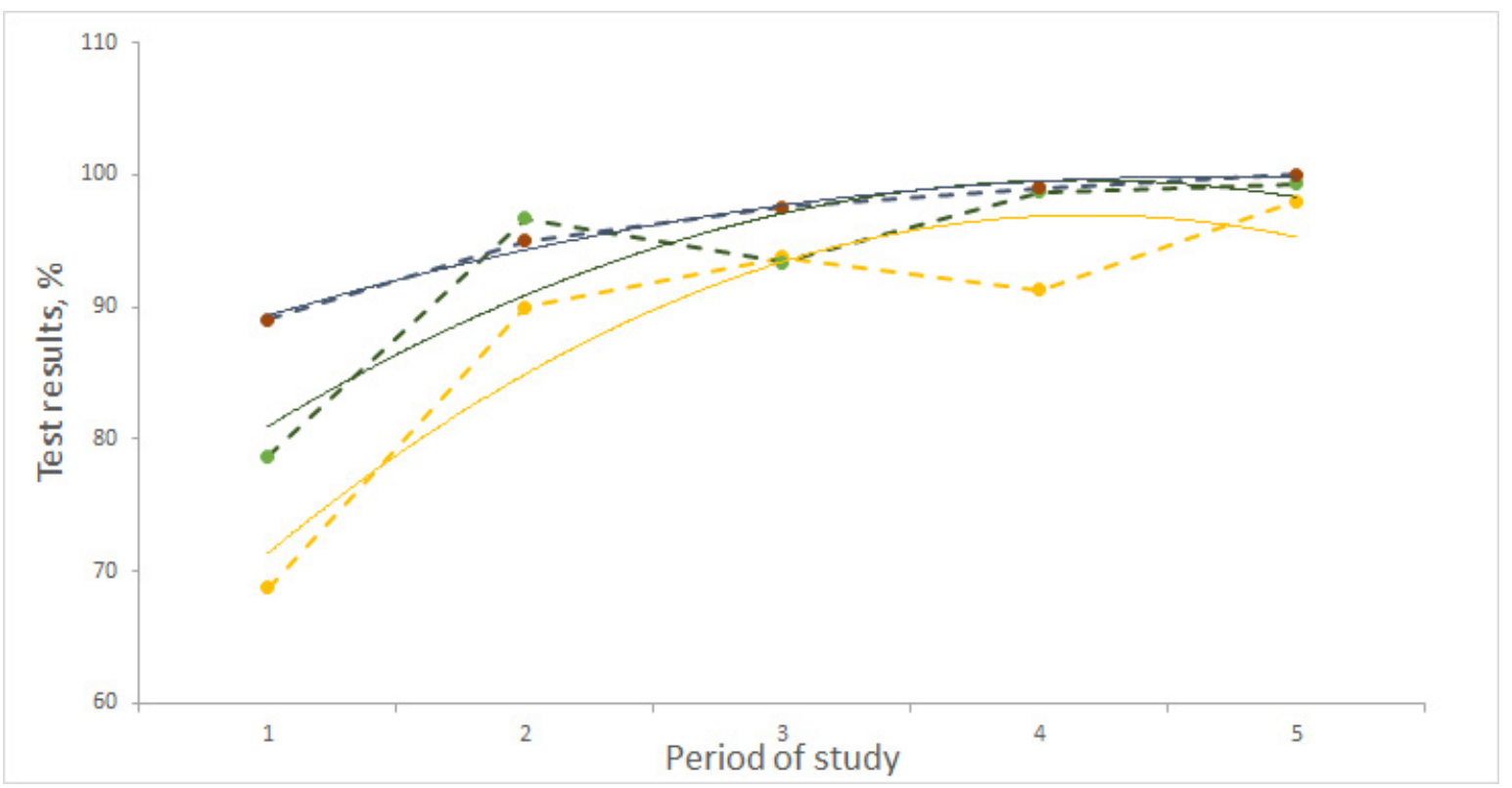

FIGURE 2. Learning curves obtained in the experiment (polynomial approximation)

( _ _ _. - raw data (LC Pre-Intermediate); __ - approximated data (LC Pre-Intermediate),

_ _ _. - raw data (LC Intermediate); __ - approximated data (LC Intermediate,

_. = .. - raw data (LC Upper-Intermediate); ___ - approximated data (LC Upper-Intermediate))

An analysis of the standard deviation and R2 showed that the most accurate data were obtained when constructing a polynomial approximation.

The results of the experiment as a whole show almost monotonous increase in the memorization of foreign words from one session to another, which is consistent with all known data on LC. On the average, the initial level 
of knowledge of words in the dictionary increases from the Pre-Intermediate group to the Upper-Intermediate group. Since in 5 sessions all participants in the study demonstrated knowledge close to $100 \%$, the better the group knows the language, the flatter its $\mathrm{LC}$ is.

Based on comparison of the approximations of the experimental LCs to functions of various types, it can be concluded that all of them provide satisfactory results, while, based on an analysis of the SD and R2 values, it can be argued that the polynomial approximation is more accurate.

\section{DISCUSSION AND CONCLUSIONS}

This work results in a quantitative analysis of the learning curve for foreign language learners. For data analysis, two methods of data approximation are applied: logarithmic and polynomial. The data on the dynamics of the learning process, obtained in the experiment, suggests that the developed technique can be applied in the study of foreign languages in various educational institutions.

Further studies of the learning curve and development of methods for its acquisition and analysis are planned to be conducted through gathering and using statistical data on the forgetting curves.

\section{REFERENCES}

[1] Itzhak Venezia, "On the statistical origins of the learning curve", European Journal of Operational Research 19, 191-200 (1985); https://doi.org/10.1016/0377-2217(85)90172-9.

[2] Hardon S.F., Horeman T., Bonjer H.J., Meijerink W.J.H.J., "Force-based learning curve tracking in fundamental laparoscopic skills training", Surgical Endoscopy 32, 3609-3621 (2018); https://doi.org/10.1007/s00464-018-6090-7.

[3] Linda Argote, Dennis Epple, "Learning Curves in Manufacturing", Science 247, 920-924 (1990); https://doi.org/10.1126/science.247.4945.920.

[4] Paul Simon Adler и Kim Clark, "Behind the Learning Curve: A Sketch of the Learning Process", Management Science 37, 267-281 (1991); https://doi.org/10.1287/mnsc.37.3.267.

[5] Site of the Ural Federal University named after the first President of Russia B.N. Yeltsin, https://urfu.ru/ru/.

[6] E.B. Berg, M. Kit, "Lexicography under the Nets", in Crossing Boundaries: Intercultural Communication in a Global Context: Proceedings of the International Research and Practice Conference (Pushkin State Russian Language Institute, Moscow, 2018), pp. 129-131.

[7] E.B. Berg, M. Kit, "Personal Educational Dictionary as an Interactive Learning Aid", in Problems of Modernization of Contemporary Higher Education: Linguistic Aspects. Linguistic and methodological problems and trends in the teaching of foreign languages in a non-linguistic university: Proceedings of the International Scientific Conference (Ippolitova Publishing house, OABII, Omsk, 2018), pp. 28-34. 